\title{
Role of Medicinal Plant in Human Health Perspective
}

\section{Smruti Sohani*}

Institute of Agriculture Sciences, SAGE University, Indore, India

*Corresponding Author: Smruti Sohani, Institute of Agriculture Sciences, SAGE

University, Indore, India.
Received: May 15, 2021

Published: May 24, 2021

(C) All rights are reserved by Smruti Sohani.

\begin{abstract}
Medicinal plants have been used in healthcare since ancient time. Medicinal plants play dynamic roles in their promotion disease prevention and use fit into all prevailing prevention strategies. There are even more studies and applications of herbal medicine in the treatment of diseases. Medicinal plants are a significant source of molecules with medicinal properties of the nature of phytochemical constituents, medicinal plants are valuable for treating human diseases and play an important role in healing. Natural and unique medicinal plants are used to treat various diseases and illnesses as well as produce wealth. The use of plants in the treatment of various human disorders is mentioned in Ayurveda and other Indian literature. Medicinal plants are a precious asset in the fight toward serious diseases all over the world. The present study focuses on the knowledge and awareness on uses of medicinal plants and the scientific investigation to confirm their medicinal values i.e. the role, contributions and usefulness of medicinal plants in attempting the diseases of public health importance.
\end{abstract}

Keywords: Medicinal Plants; Disease; Healthcare

\section{Introduction}

Plants' importance in traditional medicine and as raw materials in pharmaceutical manufacturing cannot be overstated. Spices are almost always used to cure diseases in non-industrialized societies. Toward the end of the twentieth century, various traditions began to obstruct the practise of natural medicine. The utilization of therapeutic plants is expanding around the world, taking into account the enormous extension of conventional medication and a developing interest in home grown medicines. Plants are utilized in medication to keep up and expand wellbeing truly, intellectually and profoundly just as to treat explicit conditions and ailments. It has been discovered that nations in Africa, Asia and Latin America utilize conventional medication to help meet a portion of their essential medical service's needs. The plant realm contributes tremendously to human wellbeing when no manufactured meds were free and when no ideas of medical procedure existed. There is in this way need to ration these plants related with native information for human turn of events and great wellbeing. Engineered drugs acquired ubiquity against green cures in light of the fact that their effective impacts, nonetheless, individuals have started to understand the advantages related with common cures.

Artificially pre-arranged medications may act rapidly, however they have results which influence human body contrarily over the long haul, though, therapeutic plants work in a coordinated or favourable to biotic with practically zero unfavourable consequences for the body. A number of plant species are being used in various human health around the world, most of the plant species contain active ingredients such as alkaloids, phenols, tannins, cryogenics, glycocides, terpeniods [1]. These additives have been used as sweeteners, anti-infections, and anti-bacterials and have been shown to be safe. The bark of Alstonia boonei, for example, includes alkaloids and achistamine, which can be used to treat fever, dizziness, and high blood pressure. Garlic (Zingiber officinale) and ginger (Allium sativum) are spicy food additions that have long been used to protect human health [2].

Medicinal plants used to maintainable human health

For thousands of years, medicinal plants have been used to treat human diseases. The value of medicinal plants and traditional health systems in resolving global health issues is becoming more widely recognised. As a result of this renewed enthusiasm, research on medicinal plants is exploding on a global scale. Humans have been using medicinal plants as a source of medicine for thousands of years. Truth be told, ancient man was completely reliant on plants for all of his medical needs, including recovery, prevention, and other types of medications, and has done so for millennia. The use of medicinal plants has had a mysterious strict significance 
and diverse viewpoints in relation to the concepts of health and infection that occurred within each culture during the evolution of human culture. For as long as 3000 years, an enormous number of plants are utilized in medical services rehearses, for example, in Conventional Medication in China, India and Africa, the vast majority of which contains remedial qualities which has been determined as such by Western norms [2]. Furthermore, a variety of plants have been used for a long time by a number of cultures who are not likely to follow western standards. The importance of medicinal plants in human health is undeniable. The World Wellbeing Association considers 252 medications to be basic and fundamental (WHO), 11\% are only of plant beginning and a critical number are manufactured medications got from characteristic forerunners. Digoxin comes from Digitalis spp., quinine and quinidine comes from Cinchona spp., vincristrine and vinblastine come from Catharanthus roseus, atropine comes from Atropa belladonna, and morphine and codeine come from Papaver omniferum [3]. It is estimated that $60 \%$ of anti-tumor and anti-irresistible drugs are now licenced or in the early stages of clinical trials are of characteristic beginning [4]. These plants offer compounds for new drugs, biomimetic synthesis development and the discovery of new therapeutic properties not yet attributed to known compounds. In most cases, the crude extract of medicinal plants may be used as medicaments [5]. Medicinal plants are regarded as rich resources of traditional medicines and from these plants many of the modern medicines are produced. For thousands of years medicinal plants have been used to treat health disorders, to add flavor and conserve food and to prevent diseases epidemics. Medicinal plants have been playing an essential role in the development of human culture. It has been estimated that more than 400 traditional plants or plant derived products have been used for the management of type 2 diabetes across the world [6].

\section{Beneficial aspect of medicinal plants}

Plant-based drugs are becoming more common throughout the world. There have been significant advancements in the neuroprotective assessment of different plants used in traditional systems of medicine as a result of modern studies on medicinal plants or medicine. Medicinal plants have already played an important role in human health security, both in ancient and contemporary cultures. It has been estimated that two-thirds of all plant species on the planet have medicinal properties [7]. World Health Organization (WHO) reported that $80 \%$ of the earth's population rely on traditional medicine for their primary health care needs, and most of this therapy involves the use of plant extracts and their active components $[8,9]$. The plant species contain medicinal property are Acorus calamus, Aegle marmelos, Aloe vera, Andrographis paniculata, Carica papaya, Cassia fistula, Cyperus rotundus, Dalbergia sisoo, Emblica officinalis, Magnifera indica, Acacia auriculiformis, Moringao lifera, Salvia officinalis, Momordica charantia, Rheum ribes L., Plumbago zeylanica, Ocimum sanctum, Solanum nigrum, Syzygium cumini and Azadirachta indica [8].

Plant-based cancer experts are now being used in the treatment of cancer. Anticancer experts such as vincristine, taxol, vinblastine, subsidiaries, irinotecan, and topotecan, as well as etoposide derived from epipodophyllotoxin, are used in clinical trials all over the world [2]. More of these lines, it was used as fixings or preparation in cooking, providing certain health benefits to humans. In economical human wellbeing the board, restorative plant has assumed an indispensable part which has prompted the developing interest in elective treatments and remedial utilization of plants [10]. Furthermore, medicinal plants are considered to be more effective in relieving certain symptoms than various forms of drugs, and they are all known to be normal. The bulk of the population of rural areas is immune to traditional pharmacological treatment, resulting in the use of plants and folk medicine. Furthermore, environmental mindfulness argues that "normal" products are harmless, and that clients are exposed to minimal health risks as a result of their use. The medicinal plants are used for treatment of various diseases because of their safety and effectiveness [11].

The plant derived drugs in modern medicine has been connected to the uses of plant derivative materials as an indigenous cure in traditional system of medicine [12]. Some of the plants have been found to possess significant antibacterial, antifungal, anticancer, antidiuretic, anti-inflammatory and anti-diabetic properties $[13,14]$. The common usage of herbal medicine and medicinal plants as a normative basis for maintaining good health in most developed countries has been well documented. Plant derived drugs are used to cure mental illness, skin diseases, tuberculosis, diabetes, jaundice, hypertension and cancer. The use of traditional medicine and medicinal plants in most developing countries, as a normative basis for the maintenance of good health, has been widely observed Oral diseases are major health problems with dental caries and periodontal diseases among the most prevalent, preventable global infectious diseases [4]. Huge numbers of people die every day in developed countries around the world from preventable or curable diseases due to a shortage of even basic health care. Undernutrition is often linked to diseases in many countries. The developing world is not a single country, but rather a collection of largely disparate countries and regions at various stages of growth.

The use of medicinal plants is on the rise all over the world, because of the enormous expansion of traditional medicine and a 
growing curiosity in herbal therapies. Plants are used in medicine to preserve and improve physical, emotional, and moral fitness, as well as to cure particular diseases and disorders. Chemically prepared medicines can function rapidly, but they have side effects that have a negative impact on the human body over time, while medicinal plants operate in an integrated or pro-biotic manner with little or no negative effects on the body [15]. The use of medicinal plants has had magical-religious importance in the evolution of human society, as well as diverse points of view on the conceptions of health and disease that existed within each culture. World Health Organization (WHO) reported that $80 \%$ of the earth's population rely on traditional medicine for their primary health care needs, and most of this therapy involves the use of plant extracts and their active components (Table 1 ) $[4,8]$.

\begin{tabular}{|c|c|c|}
\hline Plants Name & Plants Parts & Uses in Disease \\
\hline Abutilon indicum (Kanghi) & Seeds & $\begin{array}{l}\text { Seeds are used as laxative and in piles and leaves are locally applied on ulcer and } \\
\text { boils. }\end{array}$ \\
\hline Acacia catechu (Khair) & Bark & The bark of the tree is used in chronic diarrhea \\
\hline Acacia nilotica (Babul) & Twig & $\begin{array}{l}\text { The twig of the plant is used as natural tooth brush. The extract of fresh bark is } \\
\text { used as tonic. }\end{array}$ \\
\hline Adhatoda vasica (Vasaka) & Leaves & The decoctions of leaves are given to cure asthma and other bronchial troubles \\
\hline Aloe vera (Gwarpatha) & Leaves & $\begin{array}{c}\text { The peelings of the leaves are used in skin burn and gel is given orally in ulcers. The } \\
\text { fleshy part is also Used in facial creams. }\end{array}$ \\
\hline Andrographis paniculata (Kalmegh) & Plant & The plant is used for malarial fever and as liver tonic. \\
\hline Anisomelos indica (Bhandari) & Leaves & Leaves used in cough and cold. \\
\hline Anogeissus latifolia (Dhawra) & Leaves & Leaves are used in diarrhoea. Gum is used as tonic. \\
\hline Argemone mexicana (Pili Katari) & $\begin{array}{l}\text { Extract of } \\
\text { leaves }\end{array}$ & $\begin{array}{l}\text { The extract is used in various skin diseases. The latex is applied in eyes in case of } \\
\text { conjunctivitis. }\end{array}$ \\
\hline Azadirachta indica (Neem) & Seed & $\begin{array}{l}\text { Seed oil is used in skin diseases and in lice. Bark is useful in malarial fever. Tender twigs are } \\
\text { used as tooth brush. }\end{array}$ \\
\hline Boerhaavia diffusa (Punarnava) & Plant & Plant used in jaundice, urinary troubles and in skin diseases. \\
\hline Catharanthus roseus (Sadabahar) & $\begin{array}{c}\text { Leaves and } \\
\text { white flowers }\end{array}$ & The leaves and white flowers are used to reduce sugar level. \\
\hline Chlorophytum spp. (Safed Musli) & Roots & The roots of the plant are used for general weakness, as tonic and aphrodisiac. \\
\hline Curculigo orchoides (Kali Musli) & Root & $\begin{array}{l}\text { Roots are used as tonic and aphrodisiac; in leucorrhoea and menstrual irregulari- } \\
\text { ties. }\end{array}$ \\
\hline Curcuma caesia (Kali Haldi) & Rhizomes & Rhizomes are used in sprains, bruises and internal injuries. \\
\hline Cyperus scariosus (Nagarmotha) & Tubers & The tubers are used in urinary and heart troubles. \\
\hline Datura metal (Dhatura) & Seeds & Smoke of seeds inhaled in bronchial troubles. \\
\hline Gymnema sylvestre (Gurmar) & Leaves & The leaves of the plant are used in diabetics. \\
\hline Ocimum sanctum (Tulsi) & Leaves & The leaves are used to cure cough and cold and also to cure boils and ulcers. \\
\hline Phyllanthus amarus (Bhuiamla) & Plant & It is a common household remedy for the treatment of Jaundice. \\
\hline Solanum nigrum (Makoy) & Leaves & The leaves are used in skin diseases and jaundice. \\
\hline Syzygium cumini (Jamun) & Seed & Seed-powder is useful in diarrhoea, dysentery and diabetics. \\
\hline Tylophora indica (Antamool) & Leaves & The leaves are taken orally in asthma. \\
\hline Urginea indica (Jangli pyaj) & Bulb & The juice of the bulb is used in respiratory disorders. \\
\hline Vitex negundo (Nirgundi) & Leaves & The extract of the leaves is used in body pain and in skin diseases. \\
\hline
\end{tabular}

Table 1: List of some medicinal plants which are most commonly used in herbal drugs. 


\section{Conclusions and Recommendations}

Many of human civilization essential needs have been fulfilled by plants, including life-saving medicines. However, since medicinal plants are endangered by human activity and unregulated wild collection, deliberate efforts toward domestication and cultivation are recommended to maintain a good supply of these plant species. Many countries are currently undergoing significant changes in the number of people affected by diseases such as diabetes, diarrhoea, cancer, rheumatism, arthritis, jaundice, hepatic obstruction, pain, cold, cough, and so on. The condition is successfully treated with herbal plant treatments. India has diversity of aromatic and medicinal plants. Herbal plants will provide a significant amount of raw material for drug industry to use in the production of medicines. In addition to the need for medicinal plant protection, it has become essential to preserve and patent conventional expertise. So, interest for a wide assortment of wild plant species is expanding with development in human requirements, numbers and business exchange. Plants have given people large numbers of their fundamental necessities, including life-saving drug specialists. Nonetheless, therapeutic plants are undermined because of human effect and uncontrolled wild assortment, it is consequently suggested that purposeful endeavours towards training and development are fundamental for constant stockpile of medicinal plant species.

\section{Bibliography}

1. Idu M. "The plant called medicine". The $104^{\text {th }}$ Inaugural Lecture Series of University of Benin City, Nigeria. Calameo (2009).

2. Akinyemi O., et al. "Medicinal plants and sustainable human health: a review". Horticulture International Journal (2018): 94-195.

3. Singh., et al. "Role of Medicinal Plants for Health Perspective: Special Reference to Antioxidant Potential". Journal of Chemical Biology and Therapeutics (2016): 3-5.

4. Garg AK., et al. "Role of Medicinal Plant in Human Health Disease". Asian Journal of Plant Science Research (2021): 19-21.

5. Yue Zhong Shu. "Recent natural products based drug development: a pharmaceutical industry perspective". Journal of Natural Products (1998): 1053-1071.

6. Smruti S. "Herbal plants used to treat diseases in India: A review". International Journal of Pharmacy and Life Sciences (2019): 6385-6387.
7. Krishnaiah D., et al. "A review of the antioxidant potential of medicinal plant Species". Food Bio Products Process 89 (2011): 217-233.

8. Joshi B., et al. "Phytochemical extraction and antimicrobial properties of different medicinal plants: Ocimum sanctum (Tulsi), Eugenia caryophyllata (Clove), Achyranthes bidentata (Datiwan) and Azadirachta indica (Neem)". Journal of Microbiology and Antimicrobials 3 (2011): 1-7.

9. WHO. Regional office for the western pacific research guidelines for evaluating the safety and efficacy of herbal medicines. World health organization regional office for the western pacific Manila (1993).

10. Adepoju AO. "Cultivation and conservation of medicinal plants for herbal drug production". Nigeria (2017).

11. Smruti S. "Ethno Medicinal Uses and Chemical Constituents of Indian Flora: Achyranthesaspera (Latjeera)". International Journal of Science and Research (2020): 1778-1780.

12. Igoli JO., et al. "Traditional medicine practice amongst the Igede People of Nigeria. Part II". African Journal of Traditional, Complementary and Alternative Medicines (2003): 1-10.

13. Sule WF., et al. "In-vitro antifungal activity of Senna alata L. crude leaf extract". Research Journal of Biological Sciences 5.3 (2010): 275-284.

14. Timothy SY., et al. "Acute toxicity, phytochemistry and antibacterial activity of aqueous and ethanolic leaf extracts of Cassia alata L". International Research Journal of Pharmacy (2012): 73-76.

15. Sandberg F., et al. "Their origins and uses". Abingdon: Taylor and Francis (2001).

Volume 5 Issue 6 June 2021

(C) All rights are reserved by Smruti Sohani. 